\title{
THEORY AND PRACTICAL FUSION IN ENGINEERING EDUCATION
}

\author{
Adib Akl, (BE, PhD Candidate) \\ Telecommunications Department, Faculty of Engineering \\ Holy-Spirit University of Kaslik (USEK), P.O. Box 446 Jounieh, Lebanon
}

\begin{abstract}
As a result of the remarkable speed of the recent technology advancement, major innovations should be proposed for the engineering laboratory contents and delivery methods. Since telecommunications are science centered, it is essential that the telecom engineering laboratory takes as its main goal the development of skills requisite to the execution of experiments and the promotion of an understanding of the relationship between theory and practical. This paper will explore the importance of fusing theory and practical in a curriculum for telecom engineering students by highlighting the contents and method of delivery of the Advanced Transmission Systems laboratory given for telecommunication engineering students at the Holy-Spirit University of Kaslik. This laboratory combines antennas design, telephony and optical communications. Although early indications of students response have stimulated great eagerness among the teaching staff, the evaluation of the combination of three communication subjects in a single laboratory, the sessions contents and the delivery method is a continuous process.
\end{abstract}

Keywords: Antennas design, Engineering education, Practical work, Telecommunications, Theory

\section{Introduction}

Engineering is the profession in which a knowledge of the mathematical and natural sciences gained by study and experiments is applied to use, efficiently, the materials for the benefit of humanity (Wright, 2002). Many researchers have shown that practicing engineers need to be exposed to theory as well as practical providing students with greater learning opportunities (Swart, 2009). Therefore, engineering students must have a knowledge that goes beyond theory that is usually gained in laboratories. This theoretical-practical fusion into a singular body of knowledge enables them to become trained technologists, useful to the 
development of their communities (Feisel \& Peterson, 2002; Rosa \& Feisel, 2005).

In recent years, there has been modest basis on which to formulate a general approach to laboratory teaching. The development of standard laboratory equipment for engineering has done much to ease a systems approach to laboratory lessons. In fact, in order to develop a laboratorybased teaching system which provides the greatest benefit for engineering students, many requirements should be studied and analyzed; does the laboratory teacher help device problems to use in teaching? Does he encourage students curiosity? Are more questions raised than are answered? (Fishenden \& Markland, 2005; Gredler, 2005; Ornstein \& Hunkins, 2004)

In this paper, we focus on the laboratory contents and method of delivery for telecommunication engineering students at the Holy-Spirit University of Kaslik, mainly in the antennas design, telephony and optical communications which, combined in a single laboratory course, involve software simulation as well as physical manipulation. This represent an important departure from traditional forms of laboratory education. NECWin Plus software is used for antennas design due to its large interoperability capability and its simple user interface. Feedback Instruments (Feedback, 2011) are used for antennas and telephony experiments and Benchmark Electronic Systems (Benchmark, 2011) are used for optical communications experiments. These trainers was chosen due to the fact that they are powerful in digital transmission systems and they cover most communication principles and modern practice.

The remainder of this paper is organized as follows. An overview of the laboratory course and its main objectives are briefly presented. Then the laboratory contents and delivery method are detailed. Finally, assessments are discussed and conclusions are drawn.

\section{The Laboratory Course:}

The Advanced Transmission Systems laboratory given for telecommunication engineering students at the Holy-Spirit University of Kaslik includes software simulations and hardware manipulations for antennas, telephony systems and optical communications. Each of these three master courses, present in the telecom engineering curriculum, is essential in the communications field. Therefore its practical work is extremely important. Hence, laboratory sessions have to be properly updated in both instructions and equipments. In fact, the lab assignments were developed with different objectives in mind. First, the teacher has to stimulate students interest with challenging problems and experiments (Ronald, 1958). In addition, the laboratory should contribute in verifying theory, providing experience in group work, stimulating creative-thinking 
processes and affording a proper perspective of concepts (Swart \& Sutherland, 2007; Swart et al., 2005). Moreover, since the need to communicate with customers is something the engineers became aware of in their careers, students must be prepared in this domain through oral and written communications during lab sessions (Baren \& Watson, 1993; Criteria for Accrediting, 1991). Furthermore, several studies (Campbell, 2005) have shown that the combination of simulated and physical lab assignments enable students to study significant definitions of terms, become used to engineering terminology and develop consciousness of diverse engineering equipments. Therefore, simulation-based assignments should be well prepared as well as the physical assignments.

\section{Laboratory Contents and Methodology:}

\section{Antennas Design and Physical Implementation}

In the first session of the antennas and propagation laboratory, students are introduced to the simulation software used for antennas design. An overview of the software and its features are provided allowing them to become familiar with the basic requirements for an antennas design project. The first step in such a project, is to insert the parameters of the antenna. Students can describe the wire, the number of segments, sources and loads, ground type, radiation pattern, conductivity etc (Balanis, 2005). After selecting the suitable parameters, they are able to view their designed antenna with the currents on its structure using the software currents feature with the display and different viewing options, the rectangular plot of the Voltage Standing Wave Ratio (VSWR) for the input of the antenna at the voltage source connection as shown in Figure 1, the rectangular plot of the input impedance (real, imaginary, magnitude and phase) and the surface pattern for the three-dimensional representation (Balanis, 2005).

In addition to rectangular plots, different tabular data which helps to analyze the performance of the antenna are accessible:

0 Average gain test.

o Currents and location.

o Frequency.

o Antenna environment.

o Far field ground parameters.

o Input files.

o Output files.

o Network data.

o Power budget.

o Radiation patterns.

o Segmentation data.

o Source input parameters. 

o Structure impedance loading.
o Structure specification.
o Voltage Standing Wave Ratio (VSWR).

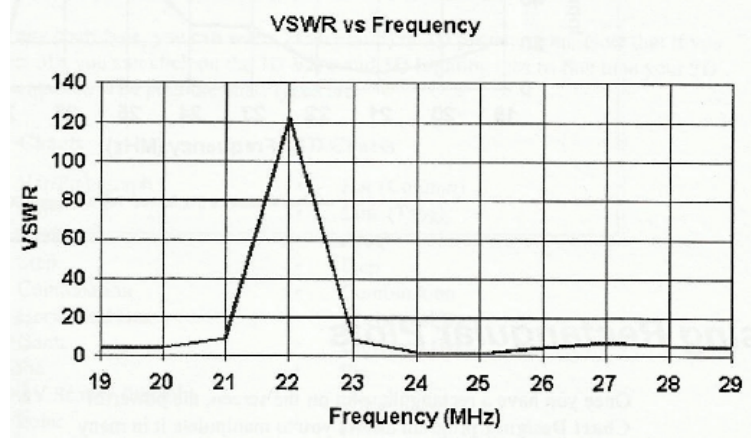

Fig. 1. Voltage Standing Wave Ratio curve with respect to frequency.

Every model should be submitted to the average gain test which performs many checks and may alert students to potential problems. If the model fails, they should verify the geometry and other parameters to ensure that guidelines are met.

In fact, rectangular plots and tabular data present a direct application to the theory earned in lectures. They are essential for results analyzing and pave the way towards a fundamental discussion during the lab session. The importance of this discussion is based on the assumption that knowledge needs a communication between the learner and the teacher (McMillan, 1997) which provides rich opportunities for students interactions, with support from teacher questions and answers.

Many antennas (monopole antenna, log periodic array, yagi antenna etc) are designed and performance evaluated. In order to reach the predefined goals of the laboratory by ensuring the software-physical fusion, students have to implement their designed antennas after achieving the software simulation. Before starting the implementation, they have to read well the overview of the lab hardware equipments. Laboratory equipments are so scheduled that a student can start an assignment and, if unable to complete the work in a single session, leave the work intact and return to it at the next session. Figure 2 presents an example of the transmitting (left) and receiving (right) antennas used in a physical lab session. The antenna towers are connected to the computer via a Universal Serial Bus (USB) connector in order to visualize the received signal strength (Balanis, 2005). The gain is measured and analyzed with respect to the antennas position. Note that time is made available for class discussions of measurement problems, results accuracy and analysis. 
During software simulations and physical lab implementations, students work in groups of two. In fact, we believe that having two (or three) students per group is a useful arrangement for telecommunication engineering assignments (Barkley et al., 2005) which maximizes the involvement of students, encourages contact between the group members, and develops reciprocity and cooperation (Thorley \& Gregory, 1994; Chickering \& Gamson, 1987).
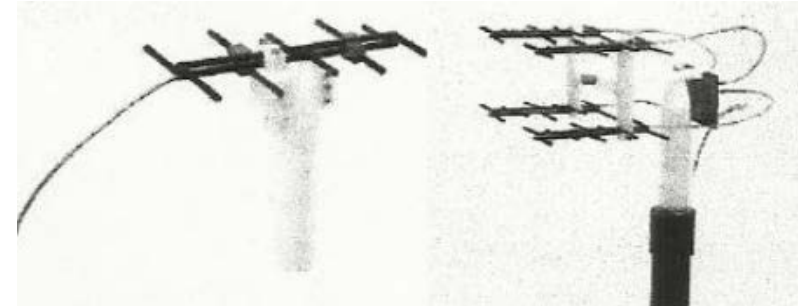

Fig. 2. Physical lab; transmitting antenna (left) and receiving antenna (right).

It was noticed in precedent laboratories that students are not well trained in the demonstration and explanation of their experimental results, and therefore, it is hard to get good reports from them. Consequently, in the presented laboratory course, in addition to the laboratory notes, a well written report based on the information appeared in the lab session is required. One important function of this laboratory is to emphasize the significance of valuable reports, containing detailed work description, by insisting on high quality through the offer of more than superficial appreciation (Kent \& Card, 1961).

\section{Telephony Systems}

Digital telephony assignments have their important role in the Advanced Transmission Systems laboratory. First, students are provided an overview which details the hardware and software installation and operation. They start by installing the hardware interface which includes (58 series telephony, 2011):

o Controller with its Voltage Selector.

o Digital Switching Center.

o Telephony Tray.

o Digital Trunk Network.

o USB Adaptor. 
Figure 3 presents the block diagram of the telephony training system connections.

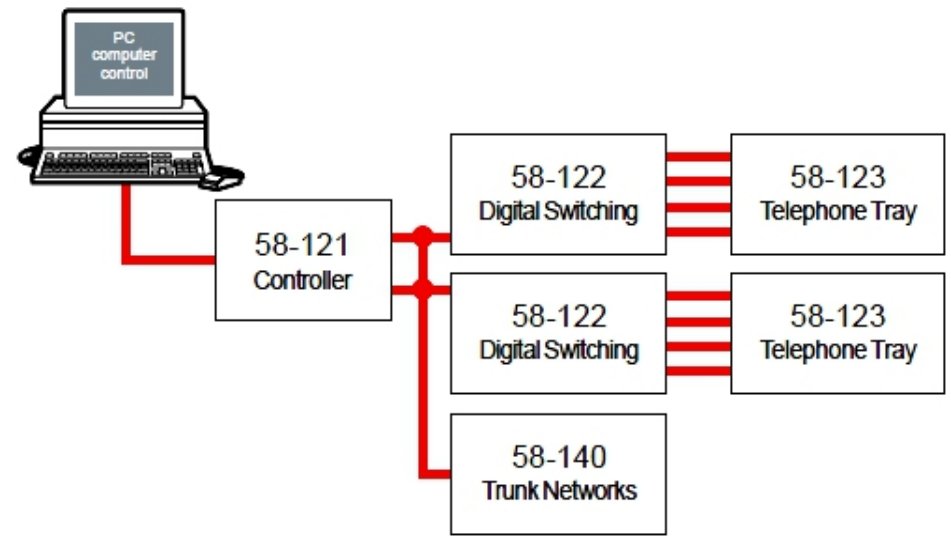

Fig. 3. Block diagram of the telephony training system connections.

Experiments with a single Digital Switching center and four Telephone Trays, as well as more advanced experiments with two Digital Switching centers and eight Telephone Trays are investigated. The Controller unit provides all the special power supplies and circuitry with the USB adaptor used as an interface to the computer. Note that Trunk Networks are needed only for the two Digital Switching centers assignments. Figure 4 presents the whole switching system.

Besides hardware equipments, a discovery software is provided with the telephony system supplying all the measurement requirements for the experiments. This hardware-software combination forms a totally integrated delivery system for teaching a wide range of telephony concepts and applications, from the characteristics of individual components to the use of complex systems, which allows the performance investigation of a wide range of experiments within the subject area (58 series telephony, 2011):

o Local signaling with basic digital switching.

o Time and space switching.

o Digital switch operation.

o Switching using RAM.

o Switch control.

o Connection of tones with Dual Tone Multi Frequency (DTMF) detection.

o Call records.

o Timing.

o Line records and numbering.

o Call accounting.

o Trunk networks with two digital switching centers. 


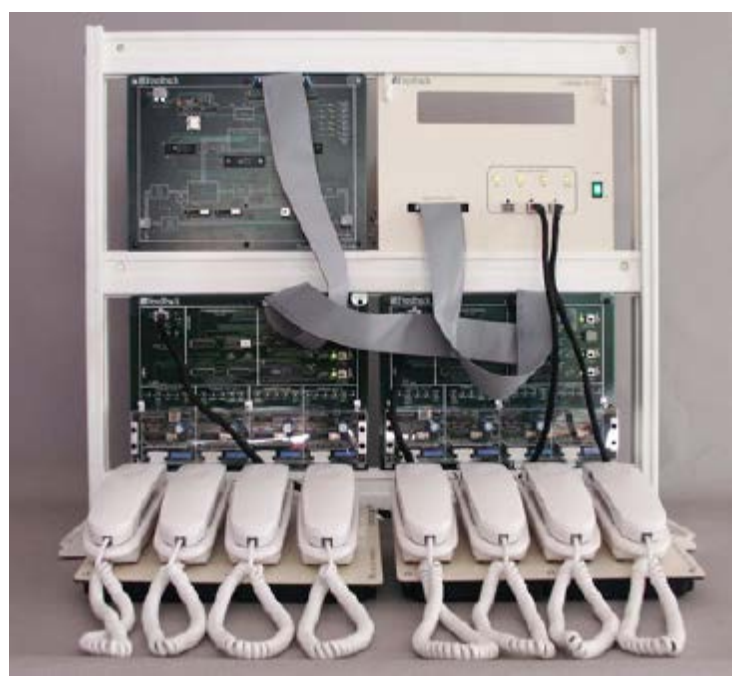

Fig. 4. The whole Digital Switching system.

Each assignment consists of a theory overview, a joint softwarehardware experiment and finally a list of questions to ensure that students have well understood the assignment. Students answers are discussed and included in the session report. Figure 5 presents a screenshot from the "Call Record" assignment showing the call states of the telephony system for each telephone line (left) and the call state transition diagram (right) showing how theory and practical are mutual in the lab assignments. In fact, students can observe the call state changes while making different phone calls using the physical equipments, which facilitates the comprehension of the call state transition diagram studied in class lectures. Thus, this modern computerbased telephony trainer easily demonstrates the contemporary digital telephony principles and forms an innovative and motivating delivery system which enables a wide range of tuition to be carried out.

\begin{tabular}{|c|l|c|}
\hline $\begin{array}{c}\text { Call } \\
\text { Record }\end{array}$ & Call State & $\begin{array}{c}\text { State } \\
\text { Code }\end{array}$ \\
\hline R1 & Idle & So \# \\
R2 & Idle & so \\
R3 & Idle & So \\
R4 & Idle & so \\
\hline
\end{tabular}

Solsct Record Recard R1

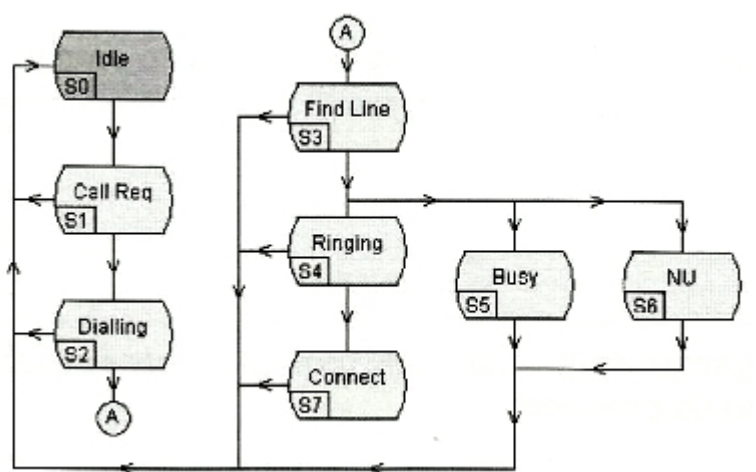

Fig. 5. Example from the "Call Record" assignment. 


\section{Optical Communications}

Optical communication systems have revolutionized the way the world communicates today. Therefore, optical communications laboratories have assumed great importance in the scenario of widespread usage of digital transmission technology. Potential entrants into this field have to be well versed and equipped to work with large-scale, real world, fiber optic systems. As in previous laboratory sessions, an overview which details the optical communication system devices used in the experiments is provided to students (Benchmark, 2011).

Plastic fiber cables are factory prepared for use. However, students learn how to prepare their own fiber optic cable in case the provided cable ends have become deformed or damaged. They have to take the given length of the fiber, strip the plastic jacket (cladding) for about $6 \mathrm{~mm}$ at each end and cut the transparent plastic material with a sharp new blade such that about 3 $\mathrm{mm}$ projects out from the jacket. This physical work encourages students enthusiasm and provides them experience in group planning and processing. After preparing their own fiber optic link, they start to install the optical communication system which consists of the power supply with its interface cable, the fiber optic link, the optical transmitter and the optical receiver. Figure 6 presents the communication system consisting of the optical transmitter, the optical receiver and a fiber optic link connecting them. A function generator is used to feed sinusoidal signals to the input of the transmitter and the received signal is observed using an oscilloscope to ensure that the decoded signal matches with the input signal.

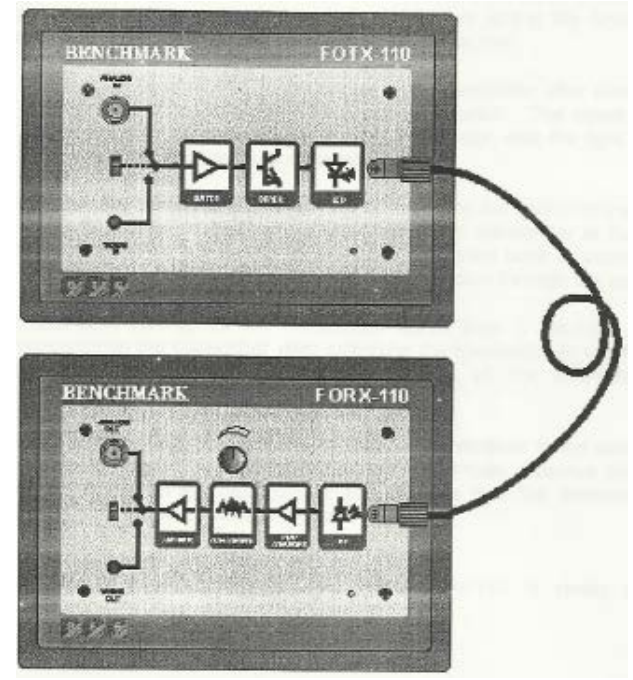

Fig. 6. Link establishment; Optical Transmitter (upper row), Optical Receiver (bottom row) and Fiber Optic Link connecting them. 
Using this optical communication system, many experiments are investigated (Benchmark, 2011):

o Fiber optic components; Light Emitting Diode (LED), Photodetector (PD) and plastic fiber.

o Setting up a small distance fiber optic link.

o Loss measurement.

o Bandwidth measurement.

The experimenter kit shown in Figure 7 is used for other basic and advanced concepts experimentations. The essential elements of the fiber optic communication system enclosed in this kit are (Benchmark, 2011):

o Voice/video coder and decoder.

o Multiplexer and demultiplexer.

o Line coder and decoder.

o Optical transmitter and receiver.

o Splices.

o Connectors and couplers.

o Converters.

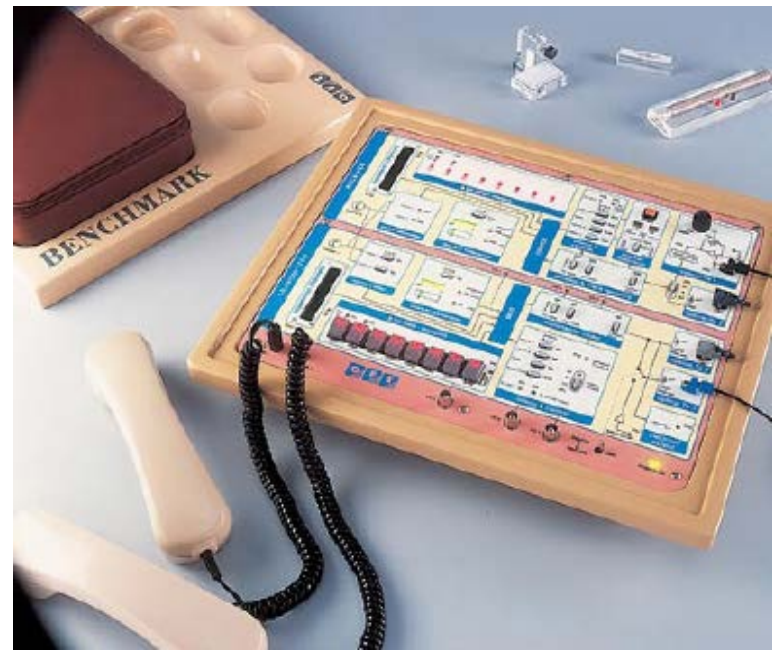

Fig. 7. BENCHMARK experimenter kit.

The easy interface to external circuitry of the experimenter kit facilitates demonstrations and experimentations in advanced concepts including (Benchmark, 2011):

o Setting up $850 \mathrm{~nm}$ and $650 \mathrm{~nm}$ fiber optic analog links and observing the relationship between the input signal and the received signal.

o Studying the effect of the gain control on the received signal.

o Measuring the link bandwidth. 
o Setting up $850 \mathrm{~nm}$ and $650 \mathrm{~nm}$ digital links and measuring the maximum bit rates supportable on these links.

o Studying losses and electromagnetic interference in optical fibers.

o Measuring the numerical aperture.

Each of the listed assignments consists of a theory overview, a physical experiment and comprehension questions to ensure that students have well understood the assignment.

\section{Assessment and Discussion}

As stated in previous sections, the aim of the Advanced Transmission Systems laboratory is the development of experimental skills and techniques in antennas design, telephony systems and optical communications.

According to our experience in this area, most of the objectives set during the preparation of the laboratory program are met. The assignments appeared to offer engineering students an opportunity to develop good technical judgment as to balance between theory and practice, a feel for the physical magnitude of things, individual thinking and an ability to be a good observer of physical phenomena.

The overview theory, hardware configuration, practical control, instruction and questions, group work and well written reports together with the computer-based instrumentation integrated in a single laboratory, form a complete package dealing with theory and practice which helps students to master fundamental principles and techniques and gain experience in modern digital communication systems.

By looking at how these cognitive skills affect the ease of comprehension among students, we were able to understand more about their weaknesses; they struggle to interpret their measurements and results and to identify the main principles surrounded in the practical work.

The presented laboratory course has had the hearted support of the engineering faculty, and it has been received with encouraging enthusiasm by the students. In fact, an early measure of their opinion revealed that they show a high degree of interest in the theoretical-physical assignments; they felt that the laboratory course was relevant to the theory done in the classroom and enjoyed the practical work, acquiring needed skills relevant to their engineering discipline.

\section{Conclusion}

The knowledge-practice theory is based on the assumption that knowledge is an interaction between the learner and the teacher. One of the major issues in designing instructions for this theory involves providing rich opportunities for experimentation with physical instruments, with peer 
interaction and support from teacher questions. Therefore, engineering students acquire a knowledge through thought and experience.

Although laboratory courses are an important part of engineering education, they are usually treated as something extra; they have not kept pace with the trend in engineering education.

In this paper, a description of the Advanced Transmission Systems laboratory course lately developed at the Holy-Spirit University of Kaslik and the importance of this lab in the telecommunication engineering curriculum are presented and discussed.

Although the lab preparation presented some difficulties which have been surmounted, the advantages gained have been significant. Our findings revealed that the presented laboratory was able to develop the understanding of the scientific method through which knowledge and practice are combined for the execution of meaningful experimental work. Thankfully, we found that most of the laboratory purposes were met. Theses purposes can be resumed by developing an ability to use experimental techniques to check theory, stimulate students interest and fix relationships more firmly in mind.

Finally, while we are tending to be certain enough to argue, on the evidence of students as well as staff opinion, that our experiment in laboratory education shows a great success, we are enthusiastic about continuing to improve our engineering laboratories.

\section{References:}

P.H. Wright, Introduction to Engineering, 3rd ed. John Wiley \& Sons, 2002, pp. 20-25.

Swart, J. "Theory versus practical in a curriculum for engineering students - A case study", AFRICON 2009, pp. 1-4.

Feisel, L.D., and Peterson, G.D., "The Challenge of the Laboratory in Engineering Education,” Journal of Engineering Education, Vol. 91, 2002, pp. 367-368.

Albert J. Rosa and Lyle D. Feisel, "The role of the laboratory in undergraduate engineering education", Journal of Engineering Education, Vol. 94, 2005, pp. 121-130.

C. Fishenden and E. Markland, "A Systems Approach to Elementary Laboratory Instruction", European Journal of Engineering Education, Vol. 4, 1980, pp. 293-302.

M.E. Gredler, Learning and Instruction - Theory into Practice. 5th ed. Pearson Education, 2005, pp. 423-429.

A.C. Ornstein \& F.P. Hunkins, Curriculum Foundations, Principles and Issues. 4th ed. Pearson Education, 2004, pp 21, 22 \& 109.

Feedback instruments Ltd. (2014). Retrieved from http://www.feedbackinstruments.com. 
Benchmark Electronic Systems (2002-2011). Retrieved from http://www.benchmark-electronics.com.

Ronald L. M., "Role of the Laboratory in Engineering Education", Report on Nec Panel Discussion, Chicago, October 14, 1958.

James Swart and Trudy Sutherland, "Fusing theory and practical in a curriculum for engineering students - A case study", AFRICON 2007, pp. 16.

A.J. Swart, R.S. Schoeman \& H. De Jager, "Assessing senior engineering students with regard to radio communication principles", presented at the EIAE 2005 conference, University of Bridgeport, Virtual Forum Online, 1020 December.

M. Robert Baren, James Watson, "Developing Communications Skills in Engineering Classes", International Professional Communication Conference, 1993.

Criteria for Accrediting Programs in Engineering in the United States, Accreditation Board for Engineering and Technology, 345 East 47th Street, NY., NY 1990-91.

J. Olin Campbell, "The Effectiveness of Simulated Electronics Laboratories for Distributed Online Learning", Department of Electrical and Computer Engineering, Franklin W. Olin, College of Engineering, 2005.

Constantine A. Balanis, Antenna Theory: Analysis and Design, WileyInterscience, 2005.

J.H McMillan, Classroom Assessment: Principles and Practice for Effective Instruction. Allyn \& Bacon, 1997, P40.

E.F. Barkley, K.P. Cross \& C.H. Major, Collaborative Learning Techniques A handbook for college faculty. Jossey-Bass, 2005, pp 16 \& 44.

L. Thorley \& R. Gregory (editors), Using Group-based Learning in Higher Education. Kogan Page, 1994, p 25.

A. W. Chickering \& Z. F. Gamson, Seven Principles for Good Practice in Undergraduate Education. AAHE Bulletin, 1987, pp. 3-7.

G. Kent, W.H. Card, "An Experiment in Laboratory Education", IRE Transactions on Education, Vol. 4, 1961, pp. 62-66.

58 series telephony info, Telephony Trainers, Feedback Instruments, England by FI Ltd, Crowborough, 2011. 